\title{
УЗНИК УСОЛЬЛАГА: ХУДОЖЕСТВЕННЫЙ ЯЗЫК К.П. РОТОВА
}

методист научно-методического отдела, Мемориальный музей-заповедник истории политических репрессий «Пермь-36» denis.podliodnov@gmail.com

Е.Д. Казанцева, заведуюший передвижной выставкой, Мемориальный музей-заповедник истории политических репрессий «Пермь-36» helenakazantseva@mail.ru

\begin{abstract}
Аннотация. Предпринята попытка проанализировать изменение художественного языка советского художника-карикатуриста Константина Павловича Ротова. Авторы находят взаимосвязь между событиями, которые влияют на судьбу художника, и изменением стилистических особенностей его работ. В статье авторы выделяют основные периоды творчества К.П. Ротова. При помощи формально-стилистического анализа творчества рассматриваются основные параметры формы и содержание карикатур и выявляются жанровые особенности, которые формируют «канон» карикатуры.

Ключевые слова: искусство заключенных; искусство ГУЛАГа; карикатура; художественный язык; визуальный язык.
\end{abstract}

\section{PRISONER OF USOLAG: THE ART LANGUAGE OF K.P. ROTOV}

D.D. Podlednov, methodist of the scientific-methodical department, The Memorial Reserve Museum of the History of Political Repression Perm-36» denis.podliodnov@gmail.com

E.D. Kazantseva, exhibition manager, The Memorial Reserve Museum of the History of Political Repression Perm-36» helenakazantseva@mail.ru

Summary. The article attempts to analyze the changes in the artistic language of the Soviet caricaturist Konstantin Pavlovich Rotov. The authors 
find a relationship between events that affect the fate of the artist and also make changes in the stylistic features of his work.

In the article, the authors identify the main periods of the work of K.P. Rotov. Using the formal-stylistic analysis of creativity, the main parameters of the form and the content of the caricatures were examined, and the genre features that form the "canon" of the caricatures were revealed.

Keywords: the art of prisoners; the art of the GULAG; caricature; artistic language; visual language.

Константин Павлович Ротов - советский художник, один из тех творцов искусства, которые были осуждены по 58-й статье УК РСФСР (контрреволюционная деятельность) и приговорены к заключению в исправительно-трудовых лагерях. В данном исследовании тема политических репрессий рассматривается с точки зрения междисциплинарной парадигмы: с одной стороны, рассматриваются этапы его биографии и периоды творчества, с другой стороны - с точки зрения искусствоведения - важно понять, как меняется его художественный язык и какие факторы на него влияют. Именно арест и период заключения являются той переломной точкой, когда язык его творчества начинает меняться средства художественной выразительности становятся более аскетичными, в сюжетах появляются новые нарративы. В статье рассматривается следующий исследовательский вопрос: как период заключения в исправительно-трудовом лагере повлиял на художественный язык К.П. Ротова?

\section{Карикатура как жанр искусства}

Под «карикатурой» понимается жанр изобразительного искусства (чаще всего графики, гораздо реже живописи или скульптуры), являющийся формой изобразительной сатиры и обладающий социально-критической направленностью.

Карикатура имеет довольно продолжительную историю: одним из первых карикатурных изображений можно считать «Гротескные головы» Леонардо да Винчи (1485). Художники Северного Возрождения обращаются к гротескным, абсурдным изображениям, высмеивая отрицательные черты и привычки людей (Иероним Босх «Извлечение камня глупости» (1475-1480), «Корабль дураков» (1495-1500), Питер Брейгель «Льстящие» (1592)), однако говорить о зарождении жанра еще рано. 
Официально карикатура как жанр формируется в XVIII в.: например, картины и гравюры Уильяма Хогарта высмеивали нравы английского общества («Лекция» (1736), «Взбешенный музыкант» (1741)). Особенно популярной карикатуру делает то, что она понятна для всех слоев общества, в том числе для неграмотных людей, а также благодаря запоминающимся непривычным визуальным образам сильно воздействует на эмоции зрителя. Понятность и способность воздействовать на эмоции делает карикатуру тем жанром, который используется для влияния на общественное мнение: карикатуристы подшучивают над знаменитостями и политиками; используют рисунки для нравственного воспитания, высмеивая человеческие пороки. Таким образом, карикатура как изобразительный жанр способна быстро реагировать на острые общественные вопросы, оставаясь на «волне» социальных проблем.

В XIX в. карикатурные изображения становятся постоянными спутниками публицистических текстов - в газетах распространяются сатирические рисунки с пояснительными фразами. Важную роль для газетной карикатуры играет текст - именно он помогает читателю понимать сатирический смысл изображения. При этом содержание рисунков строго цензурировалось - чтобы не допустить оскорбление власти (в это же время можно говорить о появлении неофициальной карикатуры, так как особо остроумные и злободневные рисунки передавались и перерисовывались). В России к середине XIX в. карикатуры публиковались как в серьезных периодических изданиях (журнал «Сын Отечества»), так и в специализированных - юмористических («Искра», «Гудок»).

Основная особенность искусства советского периода - его наполненность идеологией: т.е. искусство в первую очередь должно было быть проводником идей советского государства и коммунистической партии. В искусстве преобладал «социалистический реализм», провозглашающий народность, понятность для широких масс и идеологическую направленность. Советское искусство рождает новую эстетику: художники должны были воспевать строительство социалистического государства и радость труда.

В начале XX в. значимым жанром в изобразительном искусстве становится пропагандистский плакат. В 20-30-е гг. плакаты зачастую содержали карикатурные изображения. Карикатура, как и другие жанры искусства, в советское время служила идеологии - 
призывала к борьбе с внешним врагом - капитализмом, и высмеивала внутренние пороки общества - пьянство, тунеядство, бюрократизм, религиозность и т.д. При этом критика существующего политического строя при помощи сатирического изображения была невозможна: даже критика должна была соответствовать социалистической направленности. В 1930-1940 гг. значительное место занимает антифашистская карикатура.

В СССР карикатура является составляющей агитационной продукции - листовок, плакатов, газет. Для советской карикатуры характерны: политическая направленность, обращение к широким народным массам и критика «врагов революции», как внутренних, так и внешних.

В годы Великой Отечественной войны карикатура сыграла свою роль в поддержании патриотического настроения. Послевоенная карикатура обращается к бытовым и историческим сюжетам.

В 1980-е гг. карикатура вновь обращается к политической тематике, и сближается с направлением соц-арт. В 1986-1989 гг. в Воронеже были организованы первые Всесоюзные выставки художников-карикатуристов. В годы Перестройки, когда все темы стали открыты для обсуждения в средствах массовой информации, пользовались популярностью карикатуры на советских и российских политиков и знаменитостей, а также появились новые персонажи и темы (олигархи, «новые русские», мафия, коррупция и т.д.).

\section{Периодизация и анализ творчества К.П. Ротова}

В научном дискурсе четко не определены этапы творчества Константина Павловича Ротова, однако, чтобы рассмотреть влияние периода репрессий на художественный язык Ротова, нами была введена следующая периодизация:

1. Ранний период творчества (1916-1926 гг.).

2. Период зрелого творчества (1926-1940 гг.).

3. Лагерный период и реабилитация (1940-1954 гг.).

4. После реабилитации (1954-1959 гг.).

Константин Павлович Ротов родился в г. Ростов-на-Дону 4 марта 1902 г. Способности к рисованию зародились у него еще в раннем детстве. В семье стремились дать детям хорошее образование - в доме Ротовых всегда было много книг, выписывались литературно-художественные журналы. Когда юному художнику 
было около 15 лет, его рисунки опубликовали в газете «Ростовская речь» и журнале «Донская волна». В 1917 г. отец Константина Ротова, желая поощрить творческие устремления сына, отправил его рисунки в петербургский журнал «Бич». Иллюстрации были опубликованы и, как вспоминал художник, именно «первый рисунок, напечатанный в 1917 г. в “Биче”, окончательно сделал меня художником-рисовальщиком» [4].

В 1921 г. Константин Ротов был командирован на учебу в Петроградскую академию, где был принят на графический факультет, но, по собственному признанию: «Не учился, так как в ту пору среди преподавателей Академии преобладали непонятные и чуждые мне формалистические направления» [4].

В 1921-1922 гг. Константин Ротов получает первый серьезный заказ на создание иллюстраций к сказкам Г.Х. Андерсена и братьев Гримм и переезжает в Москву. С 1922-1923 гг. начинает сотрудничать с журналом «Крокодил», работа в котором продлится долгие годы. С 1928 г. он становится одним из ведущих карикатуристов газеты «Правда». Художник быстро завоевывает популярность, его приглашают во многие газеты и журналы: «Комсомольскую правду», «Красную Ниву», «Гудок», «Смехач», «Прожектор», «Огонек» и др.

Ранний период творчества характерен тем, что художник ищет собственные технические и стилистические приемы. Работы 20-х гг. раскрывают бытовые темы - сюжеты карикатур связаны с явлениями повседневности: жизнью в больших городах и в деревне, внедрением новой современной техники, урбанизацией, человеческими взаимоотношениями и т.д. В карикатурах Ротов высмеивает пьянство, хулиганство, тунеядство, коррупцию, бездумное преклонение перед высокими чинами, бескультурье, непотизм и т.д. Стилистически работы начала 1920-х довольно минималистичны и скупы на выразительные средства: художник использует тонкие линии, штриховку, лишь локально применяет цветовые контрастные элементы, людей изображает схематично. Примером может служить карикатура «В экстазе раскулачивания» (1920) - визуальный язык аскетичен: художник использует четкие линии, не обращается к цвету, отсутствуют объем и перспектива. Следует отметить, что в рисунке отражена только одна сюжетная линия (рис. 1). 

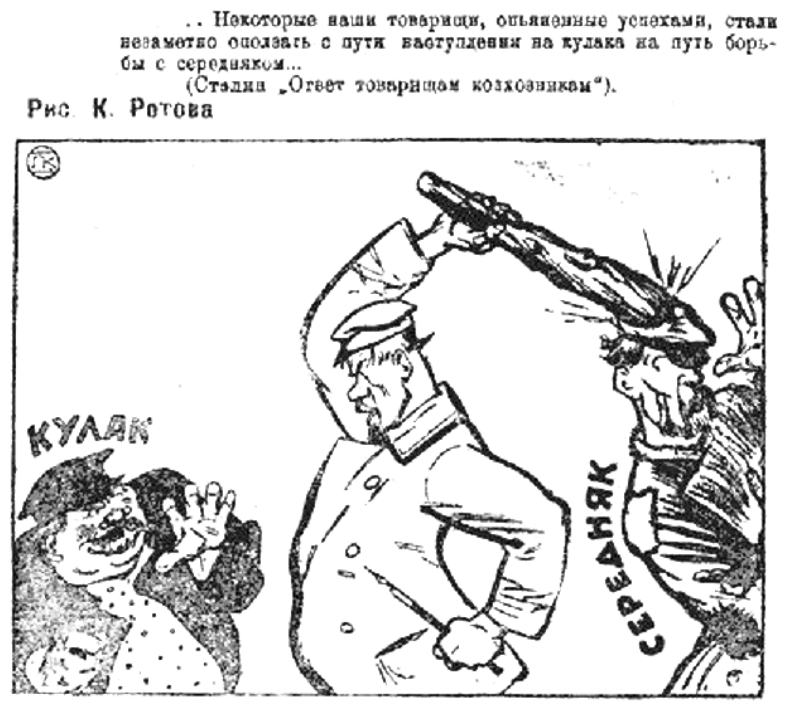

В әкставе раскулачнвання

Рис. 1. Ротов К.П. «В экстазе раскулачивания» (1920)

Период зрелого творчества: в 1930-е гг. Константин Ротов работает над книжными иллюстрациями: «Золотой теленок» Ильфа и Петрова (1931), «Белеет парус одинокий» В. Катаева (1936), «Дом переехал» А. Барто (1938), «Приключения капитана Врунгеля» А. Некрасова (1939) и т.д.

В 1939 г. Советский Союз представляет свою экспозицию на Всемирной выставке в Нью-Йорке. Среди экспонатов было панно, сделанное по эскизу Константина Павловича Ротова.

В этот период в карикатурах Ротова появляются узнаваемые особенности. Например, его излюбленным приемом становятся изображения с многофигурной композицией и сложными сюжетами. Примерами являются карикатуры «Московская экзотика» (1926), «Когда всюду ремонт» (1926), «Будни общежития» (1927). Сюжеты таких многофигурных карикатур развиваются как в замкнутых пространствах - например, на кухне общежития, так и на многолюдных улицах столичного города. Стоит отметить, что изображая большое количество людей, Ротов рисует индивидуальные черты каждого человека, т.е. лица в его карикатурах никогда не 
повторяются. Исключением служит работа «В упоении стандартом» (1935): в ней именно обезличенность черт и повторяемость одного и того же внешнего образа помогают добиться комического эффекта, что является скорее сюжетной, чем стилистической особенностью (рис. 2). Отдельно стоит отметить вытянутые формы, которые создают однородность композиции (трамвайные вагоны, автомобили, вытянутый нос у каждого человека, животные и т.д.).

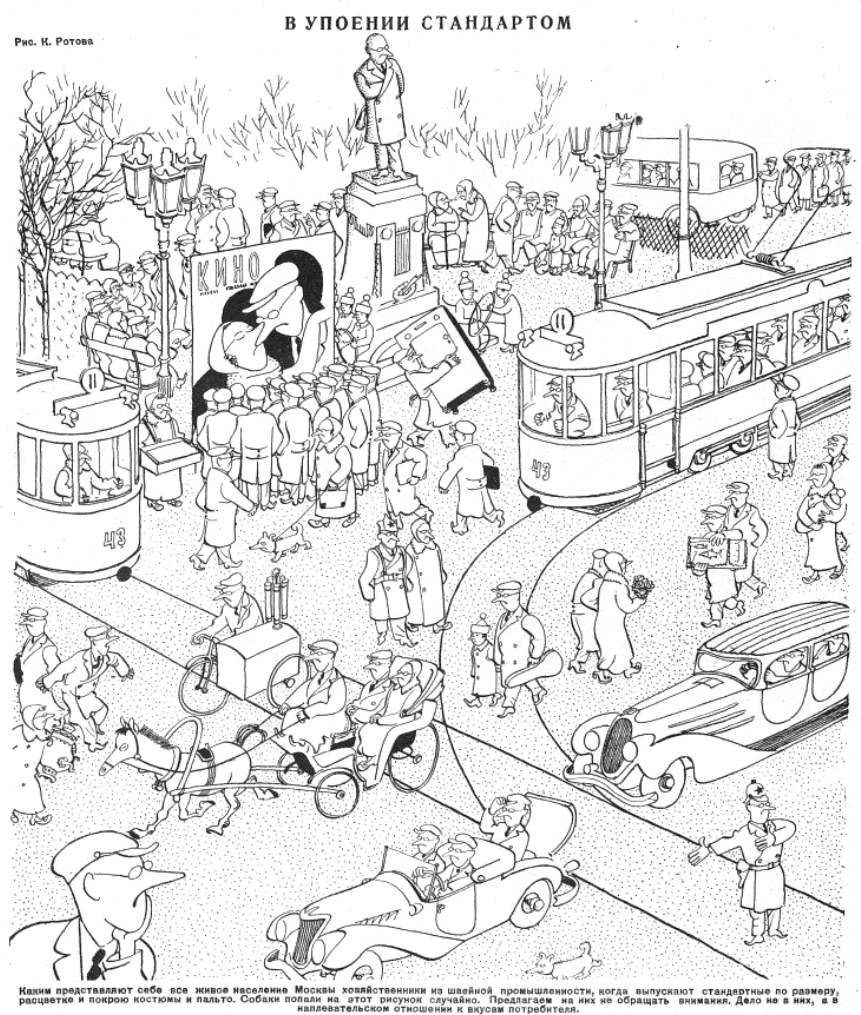

Рис. 2. Ротов К.П. «В упоении стандартом» (1935)

Отличительной особенностью периода зрелого творчества Ротова является использование ракурса сверху: примерами служат карикатуры «Во тьме времен (канцелярия каменного века)» (1927), «А говорят еще, что по мостовой ходить опасно...» (1932), «Сильное впечатление от живой лошади» (1927). 
В 1930-е гг. Ротов совершенствует мастерство, используя все перечисленные приемы, при этом круг его тем и сюжетов расширяется - он работает не только над бытовой, но и над политической карикатурой («На конференции по разоружению» (1932), «Оборонный секрет» (1937)).

В 1934-1935 гг. художник создает рисунок, который повлиял на всю его последующую жизнь - изображение лошади, якобы являвшееся карикатурой на советскую торговлю и кооперацию. Оригинальное изображение, созданное в 1934-1935 гг., не сохранилось, существует лишь рисунок, восстановленный Константином Ротовым в 1954 г., приложенный к протоколу допроса (рис. 3).

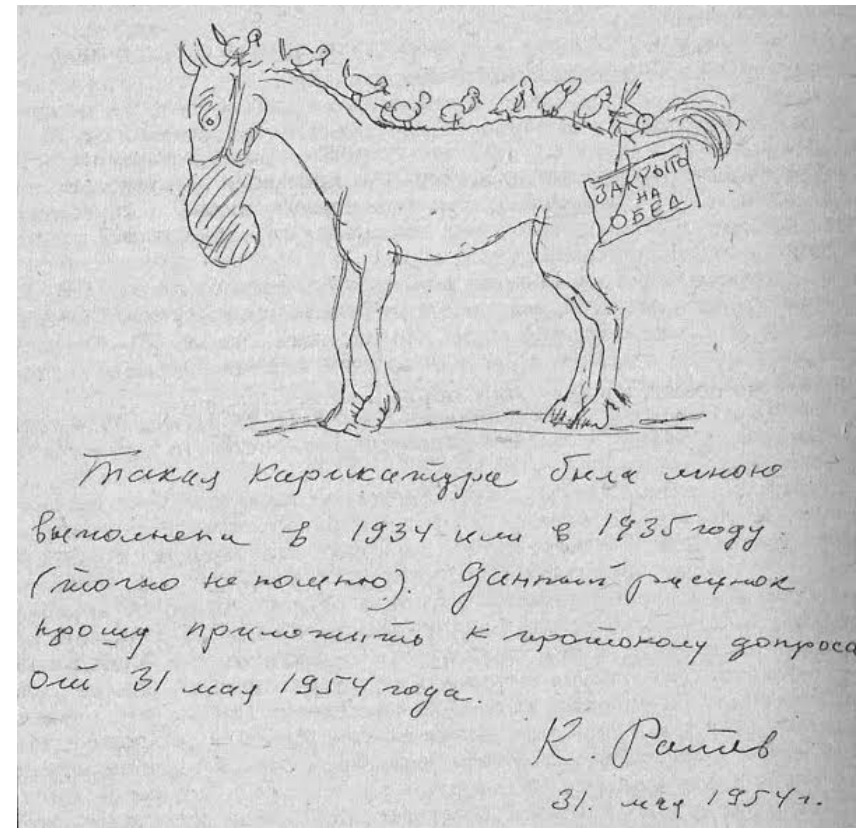

Рис. 3. Ротов К.П. Без названия (1954)

Лагерный период творчества Константина Ротова (1940-1954) - представлен совсем малым количеством сохранившихся работ: это шаржи на сокамерников (посвященные неизвестным людям), шаржи на архитектора Филиппа Тольцинера, шарж на художника К.И. Лебедева. 
1940 г. - становится переломным в судьбе художника: он был арестован по обвинению в антисоветской агитации и пропаганде за создание карикатуры, «дискредитирующей советскую торговлю и кооперацию» [1]. Карикатура не была напечатана, ее изображения и подробного описания в следственном деле не было. Во время ведения следствия Константин Ротов провел в Сухановской тюрьме НКВД одиннадцать месяцев. В начале июня 1941 г. Ротов был осужден 58-й статье УК РСФСР за шпионаж, измену Родине, пропаганду и агитацию против советской власти и приговорен к восьми годам заключения в исправительно-трудовом лагере в г. Соликамске.

Выжить в Усольлаге Ротову во многом помогла профессия: он работал художником-оформителем. Оформлял клуб к праздникам, плакаты с лозунгами и наглядной агитацией, детские игрушки (производившиеся в лагере), а также писал копии знаменитых картин, которые поступали в продажу в г. Перми [1].

Шарж на солагерников выполнен тушью и пером (рис. 4): изображены двое мужчин, статус которых мы можем идентифицировать. Портрет, который располагается сверху образ военного, о чем говорит его внешний вид: фуражка, отглаженный воротник, ухоженные усы, гордая осанка. Снизу портрет заключенного: на нем шапка-ушанка, телогрейка. Уставший вид и сутулость героя подчеркивают его эмоциональное состояние. Художник не случайно располагает шаржи вертикально: военный над заключенным - так он демонстрирует иерархию повседневности лагерной системы.

Набросок «Военный на лежанке» (рис. 5) выполнен карандашом на бумаге. Данный рисунок проработан более детально, чем предыдущий шарж, и выполнен в академической

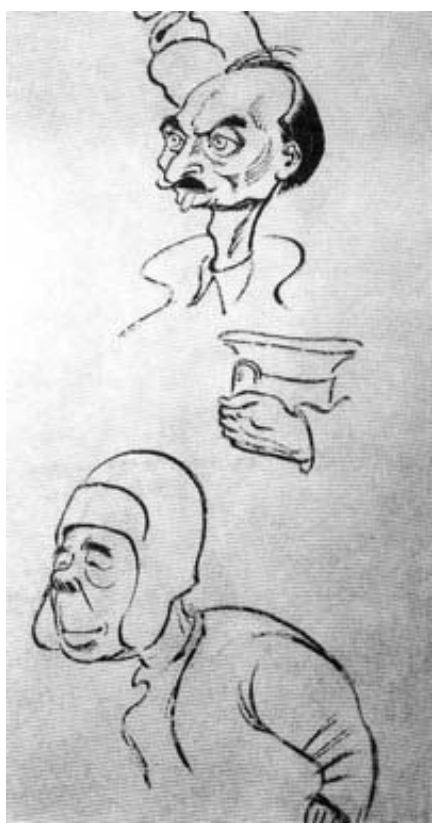

Рис. 4. Ротов К.П. Шаржи на солагерников (1940-1948) 
манере, художник обращается к объему и перспективе. Композиция рисунка статичная и открытая, что усиливает расслабленную позу героя: его руки свободно закинуты за голову, у него умиротворенное выражение лица. У зрителя создается впечатление, что даже в условиях лагеря он вряд ли страдает от каких-либо лишений.

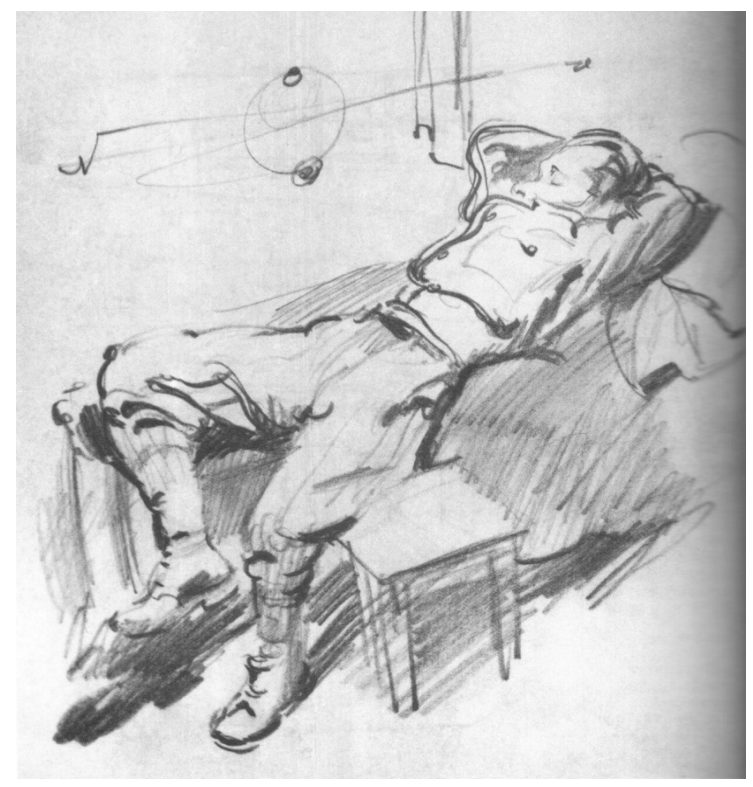

Рис. 5. Ротов К.П. «Военный на лежанке» (1940-1948)

Помимо однотонных работ, даже в лагерный период у К.П. Ротова были цветные: «Шарж на архитектора Ф. Тольцинера и технорука» (рис. 6), «Шарж на художника К.И. Лебедева» (1943), «Шарж на архитектора Ф.М. Тольцинера» (1943). Основные материалы - акварель, гуашь и графитный карандаш. В работе «Шарж на архитектора Ф. Тольцинера и технорука» художник вновь обращается к динамичной композиции: двое заключенных, один из которых управляет запряженными игрушечными лошадьми, другой же Ф. Тольцинер, сидит в игрушечной повозке, держа в руках двух кукол. Изображенные объекты не случайны, так как известно, что в Усольлаге изготавливали детские игрушки. Рисунок отличается динамикой: технорук управляет запряженными лошадьми, подго- 
няя их хлыстом, игрушечные лошади освобождаются от деревянной основы. Герои одеты в привычную для заключенных одежду: ватные штаны, телогрейка, однако на техноруке сапоги со шпорами, которые не могли быть в «гардеробе» у заключенных.

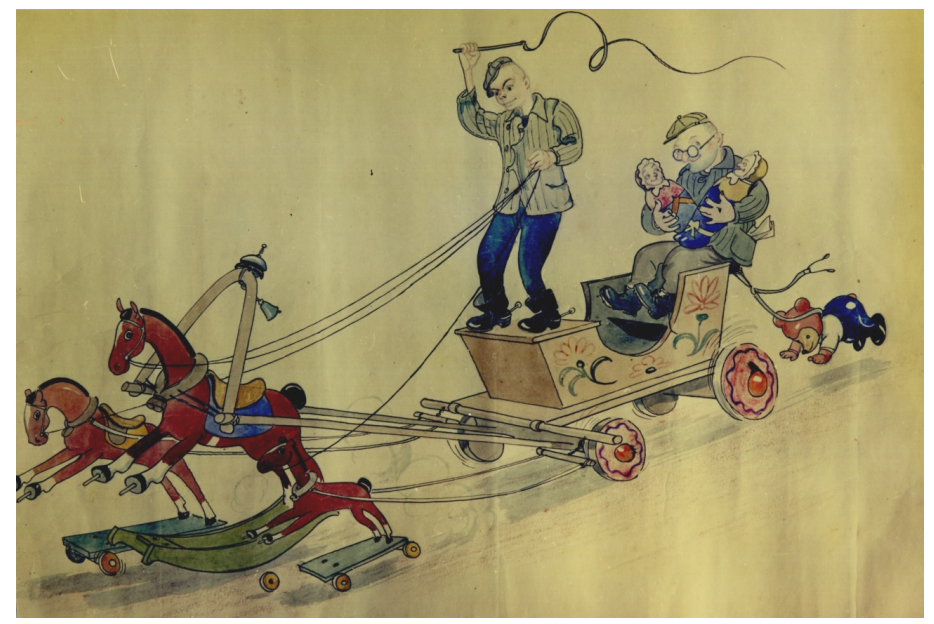

Рис. 6. Ротов К.П. «Шарж на архитектора Ф.Тольцинера и технорука» (1940-1948)

Работы «Шарж на художника К.И. Лебедева» и «Шарж на архитектора Ф.М. Тольцинера» выполнены в одной стилевой направленности и технике. Может показаться, что две данные работы выполнены с использованием цветных карандашей, но рационально предположить, что основной цвет набран акварельными красками и поверх выполнена штриховка графитным карандашом.

В 1948 г. художник был освобожден из Усольлага. Ротову, как и другим политическим заключенным, было запрещено жить в Москве и других крупных городах страны, поэтому местом его поселения был назначен г. Кимры Калининской (ныне Тверской) области. В Москве Ротов бывал проездом - надеясь получить заказ от какого-либо издательства.

В феврале 1949 г. в Москве Константин Ротов был повторно арестован и без предъявления обвинений отправлен на пожизненное поселение в поселок Северо-Енисейский Красноярского края. 
В ссылке Ротов работал художником в рабочем клубе: занимался оформлением местного дома культуры, писал картины для детского сада и библиотеки - все это приносило небольшой заработок.

\section{После освобождения из лагеря и полной реабилитации}

Константин Ротов возвращается к своему узнаваемому стилю в творчестве. В 1954 г. художник был вызван в Военную коллегию Верховного суда СССР: по памяти он восстановил злополучную карикатуру с изображением лошади. По просьбе Константина Павловича, воссозданная им карикатура была приложена к протоколу допроса от 31 мая 1954 г. Верховный суд принял решение: «Карикатура, которая рассматривалась как антисоветская, в действительности не является таковой» [1]. В июле 1954 г. Константин Павлович Ротов был полностью реабилитирован.

После освобождения Ротов вернулся в Москву: работал в журналах «Крокодил», «Веселые картинки», «Юный техник», иллюстрировал детские книги: «Дядя Степа» и «Три поросенка» С. Михалкова (1957-1958), «Про гиппопотама» С. Маршака (1958) и др. В 1958 г., после перенесенного инсульта и паралича правой стороны тела, Ротов до самой смерти (1959) пытался работать левой рукой.

Во многом его работы после 1954 г. продолжают традиции раннего периода: карикатуры затрагивают темы повседневности, такие как градостроительство («Правда, жить в этом доме неудобно, зато снаружи он, говорят, красив!» (1954), «Как выглядел бы город, если бы конструкторы-транспортники следовали вкусам некоторых наших архитекторов» (1956)), технические новшества и сложности («Затянувшийся переход» (1956)). Ротов иронически изображает отрицательные черты характера и привычки людей: высмеивает в карикатурах алкоголизм («В пригородном поезде» (1955); «Один мудрец сказал: вино сообщает каждому, кто его пьет четыре качества...» (1958) (рис. 7), бюрократизм («Рассказ о том, как председатель завкома развернул критику» (1956)), безответственное отношение к работе («Его труды и дни» (1955)), глупость («Искусство и жизнь» (1956)).

В поздний период творчества Константин Павлович Ротов не ограничивается бытовым жанром, и вновь обращается к политической тематике: «Маскируют...» (1956) и «Держись, корова из штата Айова!» (1958). 


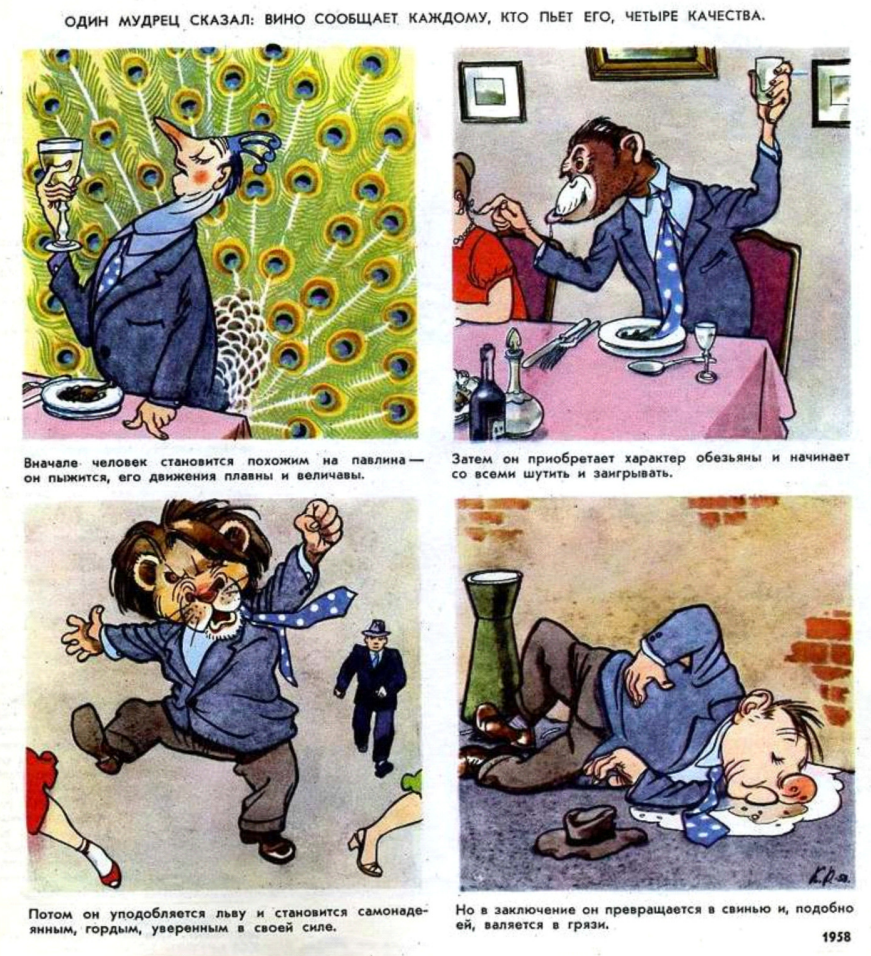

Рис. 7. Ротов К.П. «Один мудрец сказал...» (1958)

Колористические решения этого периода становятся более разнообразными - художник использует в одной работе множество не повторяющихся цветов и оттенков. Более реалистичными становятся изображения людей - художник сохраняет анатомические пропорции человеческого тела.

\section{Выводы}

В границы советского искусства необходимо включить такое вынужденное течение, как лагерное искусство, или искусство ГУЛАГа, которому свойственны отличительные черты и сюжетные особенности. Карандаш и бумага зачастую являлись единственными средствами художественного самовыражения в местах 
отбывания наказания. Анализируя сохранившиеся лагерные работы, можно прийти к следующим выводам:

- во-первых, данные рисунки являются отражением эмоционального состояния и переживаний заключенного - это могут быть портретные зарисовки, пейзажи, а также бытовые сюжеты, действие которых происходит в условиях лагеря;

- во-вторых: в таких работах мы видим визуальное свидетельство лагерной жизни: архитектуры, культуры и быта ГУЛАГа, созданное очевидцами.

Таким образом, проанализировав четыре периода в творчестве К.П. Ротова, можно выделить следующее: примерно с 1916 по 1940 г. происходит поиск и становление художественного языка художника-карикатуриста. В начале творческой деятельности он экспериментирует с визуальным языком: обращается и к статичным и к динамичным композициям, нарабатывает собственные узнаваемые приемы: многофигурность, изображение индивидуальных черт, внимание к мелким деталям рисунка. Постепенно от простых повседневных сюжетов, он обращается к политическим; сначала рисует карикатуры в одном цвете (или черно-белые), потом же он обращается к цвету, и его карикатуры становятся более красочными.

Лагерному периоду (1940-1954) были свойственны зарисовки, которые передавали повседневность лагерного быта. Стоит отметить, что даже в условиях лагеря Ротов обращается к юмористическому рисунку. Художник прибегает к зарисовкам в академическом стиле, что не было свойственно ему в другие периоды творчества. Можно предположить, что Ротов на период заключения становится художником-аутсайдером, поэтому его визуальный язык подвергается изменению. Художник находится за пределами художественных институций, т.е. не подвергается влиянию актуальных для своего времени художественных течений и тенденций.

После реабилитации (1954-1959) Ротов возвращается к открытым композициям, к цветовым колористическим решениям, к актуальным социальным и политическим темам. Важно то, что художник после освобождения из исправительно-трудового лагеря больше не обращается к лагерной тематике. Можно предположить, что его визуальный язык напрямую зависит от ситуации и обста- 
новки, в которой находится художник. Некоторые творческие люди после освобождения из исправительно-трудовых лагерей продолжают работать в данной тематике. К примеру, В.Н. Минаев «1937 год. Ждут» (1988), Б.Ш. Мкртчян «Из лагеря» (1955), «Возвращение» (1955) и др. Несомненно, не каждый из тех, кто дожил до своего освобождения, смог бы обсуждать этот тяжелый период, или возвращаться к данной тематике в своих произведениях.

Период заключения в Усольлаге является переломным для творчества К.П. Ротова: мы можем предположить, что он мало рисовал (исходя из того, что сохранилось всего лишь несколько работ), из анализа его творчества можно увидеть, что художник продолжает работать в жанре карикатуры, но иногда отходит от него в пользу академических зарисовок графитным карандашом. На период заключения художественный язык К.П. Ротова становится аскетичным (по сравнению с другими периодами его творчества), композиции в основном закрытого типа, сюжетика посвящена строго лагерному быту и архитектуре.

\section{Список литературы и источников}

1. Деева М. Пик Ротова [Электронный ресурс]. URL: https:// bessmertnybarak.ru/Rotov_Konstantin_Pavlovich/ (дата обращения: 28.08.2019).

2. Злополучная лошадь / сост. Е.А. Гуров // Библиотека Крокодила. М.: Правда, 1991. № 09 (1117).

3. Ротов К. // Мастера советской карикатуры / ред. Бор. Ефимов. М.: Правда, 1970.40 с.

4. Свиридова И.А. Константин Павлович Ротов [Электронный ресурс] // Собирая лепестки истории: сборник материалов к 100-летию еженедельника «Донская волна». Ч. 1. Редактор и его команда / Донская государственная публичная библиотека; сост. Н.Н. Зайцева. Ростов-н/Д, 2018. URL: http://donvrem.dspl.ru/archPeriodikaArtText.aspx?pid=12\&id=1539 (дата обращения: 28.07.2019).

5. Творчество и быт ГУЛАГа // Каталог музейного собрания общества «Мемориал» / ред. Л.С. Еремина, Г.П. Конечна, Е.Л. Новицкая. М.: Звенья, 1998.

6. Фонд ГКБУК «Пермский краеведческий музей». ПОКМ-19229/782, ПОКМ-19229/783. 